\title{
Computer Simulation of an Ammonia-Water Absorption Cycle for Refrigeration: Using a Distillation Tower to Replace the Generator
}

\author{
You-Im Chang1, Lin-Chia Wu1, Cherng-Chiao Wu1, Larry K. Jang2* \\ ${ }^{1}$ Department of Chemical Engineering, Tunghai University, Taiwan \\ ${ }^{2}$ Department of Chemical Engineering, California State University, Long Beach, CA, USA \\ Email: *Larry.Jang@csulb.edu
}

How to cite this paper: Chang, Y.-I., Wu, L.-C., Wu, C.-C. and Jang, L.K. (2020) Computer Simulation of an Ammonia-Water Absorption Cycle for Refrigeration: Using a Distillation Tower to Replace the Generator. Energy and Power Engineering, 12, 237256.

https://doi.org/10.4236/epe.2020.126015

Received: May 3, 2020

Accepted: June 5, 2020

Published: June 8, 2020

Copyright $\odot 2020$ by author(s) and Scientific Research Publishing Inc. This work is licensed under the Creative Commons Attribution International License (CC BY 4.0).

http://creativecommons.org/licenses/by/4.0/

\begin{abstract}
By using a distillation tower as the regenerator, the coefficient of performance (COP) of the ammonia-water absorption refrigeration cycle is calculated in this work. Two types of distillation towers, namely an equilibrium-stage tower with a total condenser and a packed-bed tower with a partial condenser, are used in the cycle. From the simulation results, it is found that both types of distillation towers can successfully increase the COP of the cycle due to increased ammonia concentration in the vapor phase of the ammonia-water refrigerant. It was also found that the tower equipped with a partial condenser provides higher COP than that of the tower equipped with a total condenser. The value of COP can be further increased when the generator is replaced by the packed-bed tower in this water-ammonia absorption cycle. The effects of the mass flow rate ratio of $\mathrm{NH}_{3} / \mathrm{H}_{2} \mathrm{O}$, stage number, reflux ratio and energy duty of the tower on the COP of the cycle are also studied in the present paper.
\end{abstract}

\section{Keywords}

Simulation, Ammonia-Water, Absorption, Refrigeration

\section{Introduction}

Conventional refrigeration cycles using vapor compressors are known to consume electricity intensively, particularly during hot summer season. Local engineers in Taiwan have a renewed interest in the alternative approach of using absorption type of refrigeration cycle that does not demand electricity intensively to tackle this problem. 
Because of its high solubility and heat of vaporization, the ammonia-water solution can serve as the refrigerant in this absorption refrigeration cycle. Absorption of ammonia is accomplished by increasing the pressure on the liquid phase, which consumes much less energy than the conventional vapor-compression type of refrigeration cycle. Several works on improving the coefficient of performance (COP) of the ammonia-water absorption refrigeration cycle have been published in the past two decades [1] [2]. For example, J. A. Rossa and E. Bazzo [3] analyzed a small-scale ammonia-water cogeneration system consisting of an absorption chiller connected by a thermosiphon heat exchanger which replaced the original natural gas burning system. It was proved that the thermal efficiency of their modified system can be increased $67 \%$ relative to a single natural-gas microturbine. Kong et al. [4] designed a refrigeration system equipped with a single ammonia-water absorption chiller of complete condensation, and found that the COP values achieved by their new device are located between 0.32 and 0.36. Hong et al. [5] studied the performance of ejector-absorption combined refrigeration cycle. They showed that the COP of the cycle is $30 \%$ higher than that of the conventional single-effect absorption refrigeration cycle at the same working conditions. Ouadha and EI-Gotni [6] had examined the feasibility of using waste heat from marine Diesel engines to drive an ammonia-water absorption refrigeration system, and found that the COP of the cycle increases with the increase of the generator temperature to a value of 0.65 , which is the upper limit COP performed by a conventional ammonia-water refrigeration system. By combing with an ejector-absorption system, Oza and Bhatt [7] found that COP of the combined cycle is improved by $14.98 \%$ to $33.47 \%$ compared to the conventional cycle. Since reusing the wasted engine heat is a useful method of energy conservation currently, Kaewpraduba et al. [8] adopted the Toyota 3RZ-FE engine to produce exhaust gas in their absorption refrigeration system. They found that the highest COP of 0.275 is reached at an engine speed of $1400 \mathrm{rpm}$, and that the decreased refrigerant temperature at the condenser outlet helps to increase COP. Wijaksana et al. [9] conducted a series of experiments of investigating the effect of ammonia concentration on the performance of this ammonia-water absorption refrigeration system. They found that increasing the ammonia concentration can increase COP, and the highest COP resulted is 0.829 at $59 \%$ ammonia concentration. Babu et al. [10] found that the maximum COP can be obtained at lower condenser and higher evaporator temperatures, which can be achieved by decreasing the rate of the refrigerant fluid ammonia in the condenser and evaporator. However, there is an increased risk of the potential generation of explosive mixtures due to the presence of hydrogen. Since the results of the above works indicate that the operating conditions of the generator such as temperature, pressure and mass flow rates of water and ammonia play a major role in determining the COPs of the whole cycle (which can be controlled by the governing operating principles of distillation towers), it reminds us that the generator of the cycle may be replaced by a distillation tower. This idea was first 
innovated by Kaushik and Bhardwaj [11] who added a rectifier on the top of generator. From the results of their theoretical analysis, they found that an increase of condenser temperature can improve the performance of the cycle at higher generator temperatures. Then, by assuming that the refrigerant vapor leaving the rectifier enriched with a $99.5 \%$ ammonia concentration when the temperature of absorber was fixed at $35^{\circ} \mathrm{C}$ and the generator pressure was kept between 1.03 $\mathrm{MPa}$ to $2.07 \mathrm{MPa}$, Clerx and Trezek [12] found that the generator temperatures must be greater than $120^{\circ} \mathrm{C}$ in order to obtain a COP value greater than 0.5 . Later on, in order to avoid the generator temperature in excess of $150^{\circ} \mathrm{C}$ in their water-ammonia system equipped with a solar cooling system, Best and Hernandez [13] invented a novel type of generator consisting of two parts: a rectifier and a falling film heat exchanger, and proved that their unit's COP can be always operates higher than 0.55 when the generator temperature is kept between $80^{\circ} \mathrm{C}$ and $100^{\circ} \mathrm{C}$.

Even many good computer algorisms were already written down to investigate the effect of changing various operating parameters (for example, the temperature and the refrigerant flow rate) on cycle's COPs (Raghuvanshi and Maheshwari [14], Cai et al. [15] and Habibzadeh et al. [16]), but since the effect of changing these parameters on the performance of the distillation tower can be simulated by using the available software such as Aspen [17]. Darwish et al. have analyzed the performance of the cycle by using the Aspen plus flowsheet simulator successfully [18]. A very good agreement between the simulator's results and the experimental measurements was found. The effect of separator (input) heat duty on the COPs agrees well with the reported experimental data with a maximum percentage deviation of $1.8 \%$. They also found that introducing a throttling process directly before the separator can alleviate the separator heat load and enhance the COP by up to $20 \%$ (i.e. from 0.45 to 0.54 , see Fig. 9 of ref. [18]). Hence, we adopted this software (Aspen version-10.0) to simulate the COPs of the present modified ammonia-water absorption refrigeration cycle equipped with four types of distillation tower (i.e., flash drum, equilibrium stage distillation column followed by a total condenser, equilibrium stage distillation column followed by a partial condenser, and a packed column) under different operating conditions. The results of simulation done in this work will show that the replacement of the generator by the packed-bed tower can give the best COPs in general.

\section{Principle of Ammonia-Water Absorption Refrigeration Cycle}

The schematic diagram of the absorption cycle for refrigeration is illustrated in Figure 1, at which ammonia is served as the refrigerant and water is served as the absorbent solvent. In this cycle, the evaporation (i.e. receiving latent heat at low temperature, $\Delta \mathrm{H}=23.4 \mathrm{~kJ} / \mathrm{mole}$ for ammonia at normal pressure) and condensation (i.e. releasing latent heat at high temperature) processes take place at a 


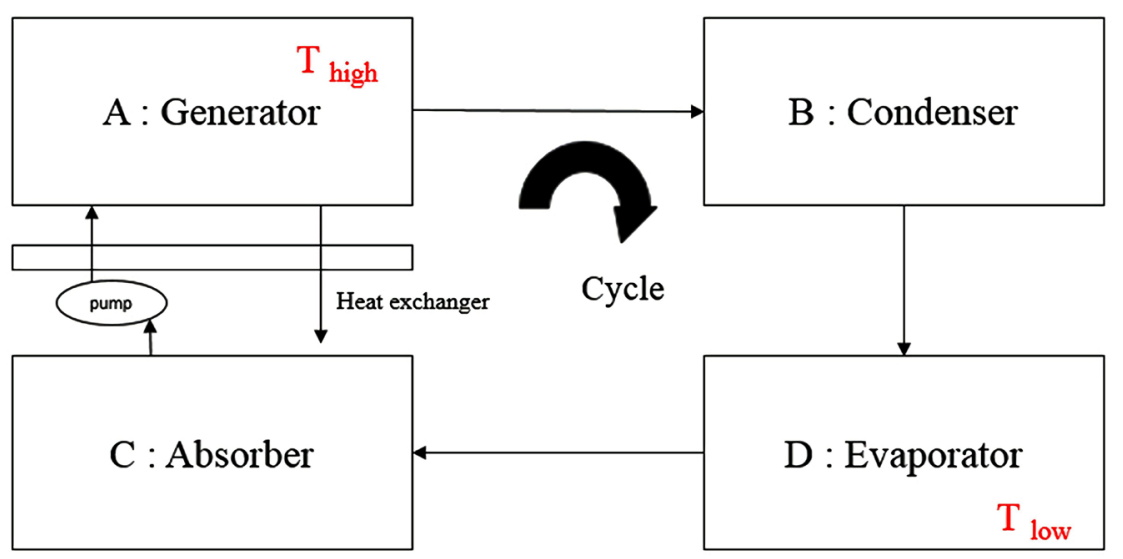

Figure 1. Schematic diagram of the ammonia water absorption cycle for refrigeration.

constant pressure, respectively. When ammonia vapor leaving the evaporator, it will be readily absorbed into the low temperature water in the absorber, where the heat of dissolution is released (i.e. $\Delta \mathrm{H}=-30 \mathrm{~kJ} /$ mole for ammonia at $25^{\circ} \mathrm{C}$ ). This strong $\mathrm{NH}_{3} / \mathrm{H}_{2} \mathrm{O}$ solution is then pumped to the higher pressure generator. Because of the reduced solubility of ammonia in water at this high temperature generator, the refrigerant vapor will leave from the solution. This vapor then passes to the condenser and the weakened $\mathrm{NH}_{3} / \mathrm{H}_{2} \mathrm{O}$ solution is returned to the absorber. In order to reduce the heat required in the generator, the returning weak solution will pass through a heat exchanger to pre-heat the strong $\mathrm{NH}_{3} / \mathrm{H}_{2} \mathrm{O}$ solution. In the condenser, the $\mathrm{NH}_{3}$ vapor will be liquefied after releasing its latent heat. Then, the $\mathrm{NH}_{3}$ refrigerant will enter an evaporator of low pressure and temperature and expand isentropically, where the heat necessary for the evaporation is taken from the cold source. Therefore, because of the equipped heat exchanger, the mechanical work done on the compression of strong $\mathrm{NH}_{3} / \mathrm{H}_{2} \mathrm{O}$ solution in this cycle will be less than that of the conventional vapor-compression cycle (i.e. the reversed Carnot cycle), but a heat input to the generator is required.

In the above absorber as shown in Figure 1, because the partial pressure of the weak $\mathrm{NH}_{3} / \mathrm{H}_{2} \mathrm{O}$ solution is low, hence most of $\mathrm{NH}_{3}$ vapor from the evaporator can be absorbed into water at this absorber. In the generator, since the solubility of $\mathrm{NH}_{3}$ in the strong solution decreases with the increase of temperature, hence most of absorbed $\mathrm{NH}_{3}$ vapor will be vaporized from solution and then passes into condenser. However, since the absorbent water will be also vaporized simultaneously when leaving the generator, the concentration of $\mathrm{NH}_{3}$ in the vapor phase refrigerant will be reduced. With this decreased concentration of $\mathrm{NH}_{3}$, because less heat will be released from condenser and taken from the cold source in the generator consequently, and the $\mathrm{COP}$ of the whole cycle will be decreased. In order to make the refrigerant leaving the generator rich in $\mathrm{NH}_{3}$ vapor, it reminds us to displace the generator by a distillation tower as mentioned above. Through this device, the water vapor can be condensed and refluxed to the tower, and therefore the vapor leaves the tower will be richer in $\mathrm{NH}_{3}$ refrigerant. Since 
the available commercial software Aspen adopted popularly by chemical engineers now, the authors intend to adopt it to investigate this replacement effect in present paper.

\section{Simulation}

Figure 2 shows the schematic diagram of the aforementioned ammonia-water absorption refrigeration cycle analyzed in the present simulation. As illustrated in Figure 2, the strong $\mathrm{NH}_{3} / \mathrm{H}_{2} \mathrm{O}$ feed solution leaves the absorber and subsequently enters the distillation tower which replaces a conventional generator. The top refrigerant enriched in $\mathrm{NH}_{3}$ leaves the distillation tower and enters the condenser, while the bottom effluent (i.e. weak $\mathrm{NH}_{3} / \mathrm{H}_{2} \mathrm{O}$ solution) is delivered to a heat exchanger to pre-heat the strong solution from the absorber. In the condenser, the $\mathrm{NH}_{3}$ refrigerant releases the latent heat and is then liquefied before entering a flash drum, which represents the evaporator of the cycle. After receiving heat from the surroundings in the flash drum, the liquefied refrigerant enters a mixer (i.e. which represents the absorber of the cycle) in which it is mixed with the weak solution from the heat exchanger. Since the absorption of ammonia in water is exothermic, a condenser is added after this mixer to prevent overheating of the solution. To eliminate the vapor content in the $\mathrm{NH}_{3} / \mathrm{H}_{2} \mathrm{O}$ strong solution leaving the mixer and minimize the work consumed in the subsequent pumping step, a flash drum is added in this process. In this flash drum, the vapor content (usually with very small amount) is recycled to the strong solution, while the bottom effluent is pumped to the heat exchanger. To adjust the temperature of the solution leaving the heat exchanger, an additional condenser is added to the flow paths of the strong solution and the weak solution, respectively.

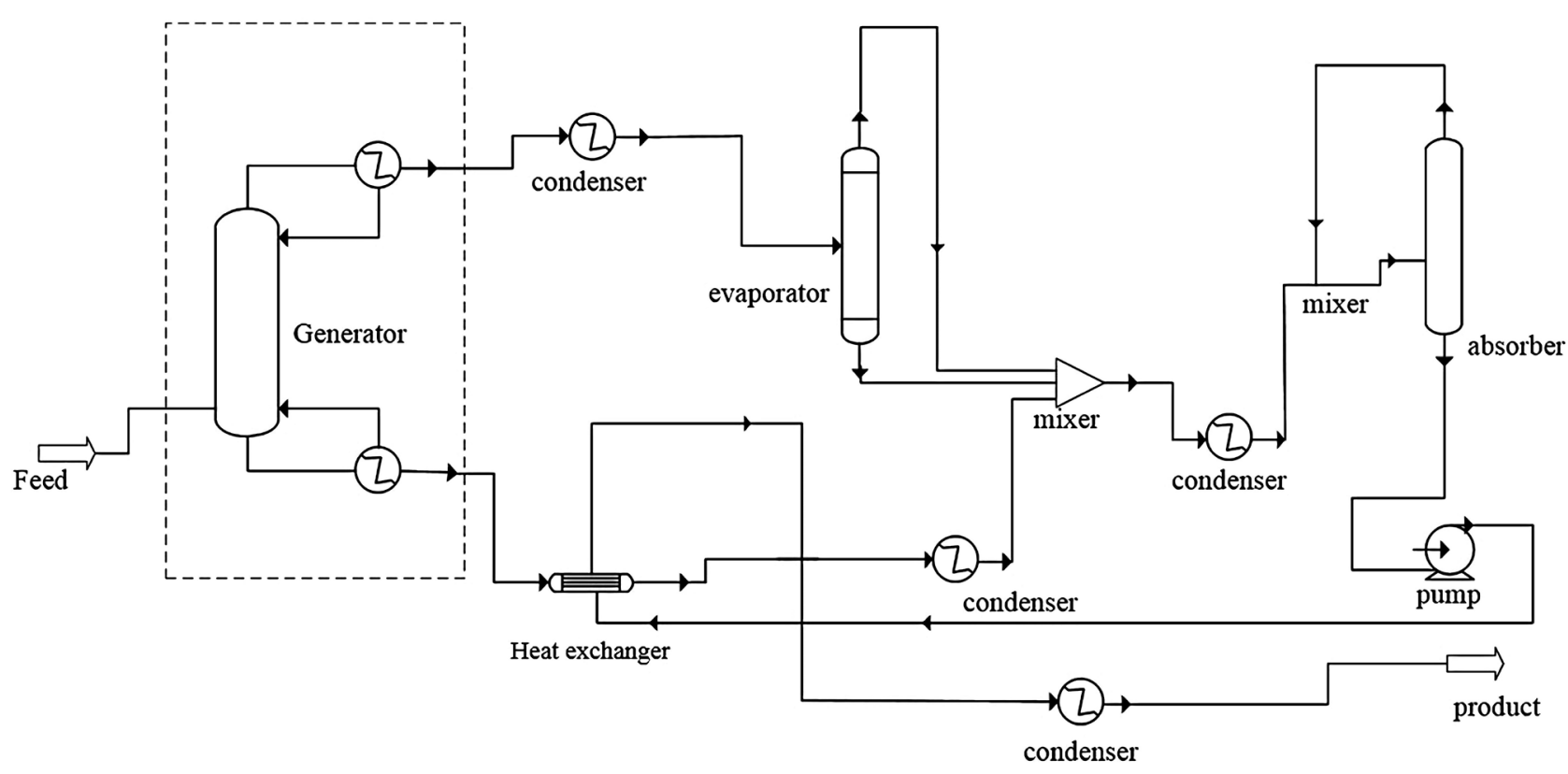

Figure 2. Computer simulation flow sheet of the ammonia water absorption cycle for refrigeration adopted in the present paper. 
In the following computer simulations, the values of different control variables of the distillation tower (i.e., temperature, pressure and mass flow rate) are varied. The present open-loop sheet in Figure 2 is termed "closed-loop" when the conditions of the product solution (shown at the right bottom side) are the same as those of the feed solution (shown at the left side of the sheet).

In the present simulation, the COP of the cycle is defined as [1] [2]:

$$
\begin{aligned}
\mathrm{COP}= & \text { Heat required in the evaporator }(\mathrm{kcal} / \mathrm{hr}) \\
& \text { Energy duty of the distillation tower }(\mathrm{kcal} / \mathrm{hr})
\end{aligned}
$$

The following assumptions are made in the present simulations:

- Feed flow rate: $1.0 \mathrm{kmol} / \mathrm{hr}$.

- Distillation tower pressure: 17 bar (gauge).

- Condenser exit temperature: $40^{\circ} \mathrm{C}$.

- Evaporator temperature: $7^{\circ} \mathrm{C}$.

- Absorber temperature: $40^{\circ} \mathrm{C}$.

- Thermodynamic package: Sour Peng-Robinson Equation of State.

For the ranges of temperature and pressure adopted in the absorber and evaporator in Figure 2, it is found that the highest solubility of $\mathrm{NH}_{3}$ in $\mathrm{H}_{2} \mathrm{O}$ is $X$ $=50 / 50$ (i.e. expressed in mass flow rate ratio) [19]. Therefore, only a few selected values of $X \leq 50 / 50$ are considered for the strong $\mathrm{NH}_{3} / \mathrm{H}_{2} \mathrm{O}$ solution entering the distillation tower in the present work.

\section{Results and Discussion}

Four different kinds of distillation tower (i.e., flash drum, equilibrium stage distillation column followed by a total condenser, equilibrium stage distillation column followed by a partial condenser, and a packed column) are proposed to replace the conventional generator as shown in Figures 3(a)-(d). Computation of COPs is conducted using the simulation conditions mentioned above.

\subsection{Flash Drum}

The effects of changing the operating temperature $\left(90^{\circ} \mathrm{C}-145^{\circ} \mathrm{C}\right)$ of the flash drum in Figure 3(a) on the COPs of the cycle for the various feed concentrations (i.e., different $X$ values) are shown in Figure 4.

For $X=50 / 50$ as shown by curve 1 in Figure 4, it is found that the COPs (0.55 - 0.65) of the cycle increase with increasing operating temperature $\left(90^{\circ} \mathrm{C}-94^{\circ} \mathrm{C}\right)$ because of the increased amount of $\mathrm{NH}_{3}$ generated in the vapor phase of this flash drum. When the operating temperature is lower than $90^{\circ} \mathrm{C}$, which is the saturation temperature corresponding to the assumed tower pressure $17 \mathrm{bar}$, no ammonia vapor is generated in the drum and, therefore, COP cannot be obtained from the computer simulation [19]. Meanwhile, when the operating temperature of this flash drum is greater than $94^{\circ} \mathrm{C}$, the concentration of ammonia in the vapor phase is diluted by the increased amount of water vapor volatilized simultaneously at this high temperature. Therefore, no evaporation effect of ammonia refrigerant is observed in the subsequent. 


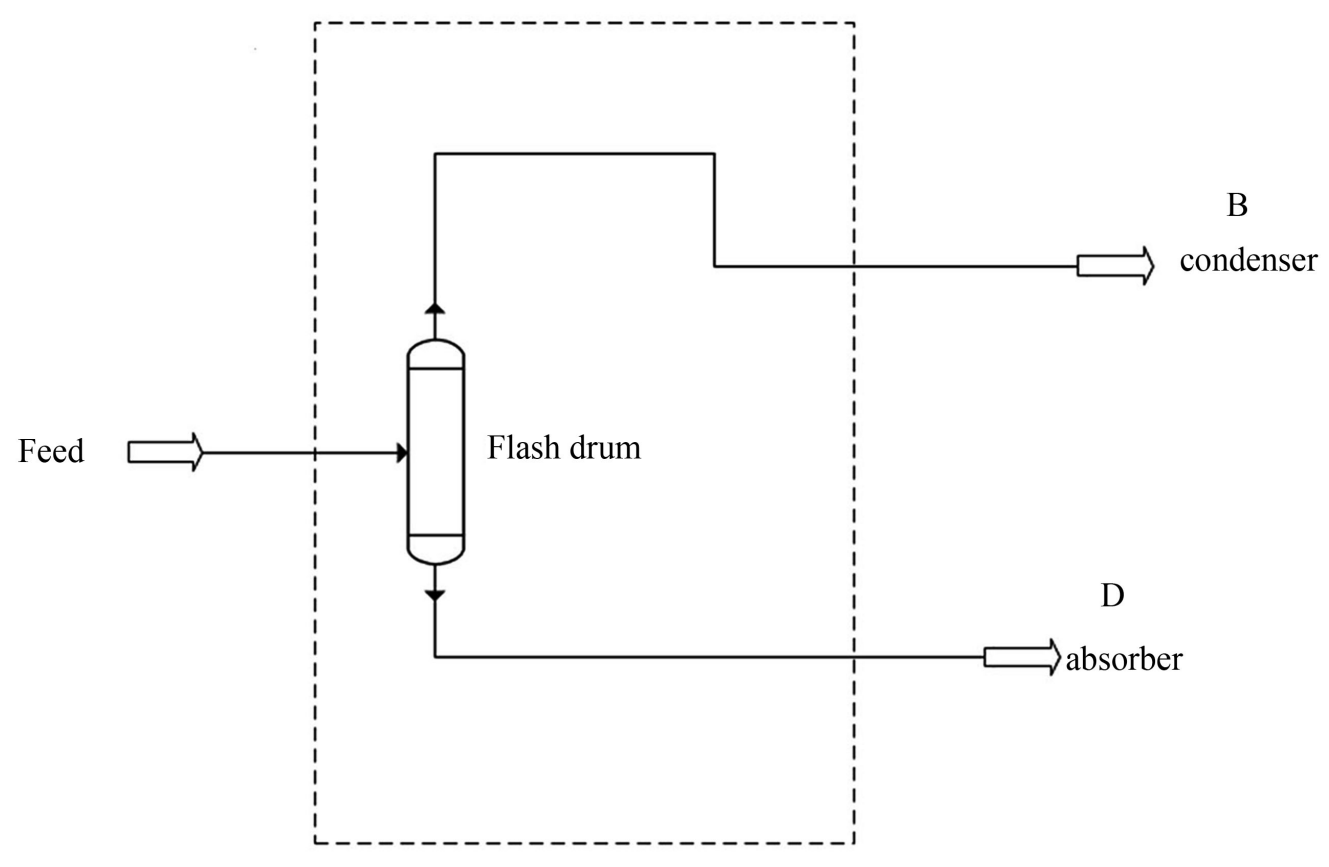

A

Generator

(a)

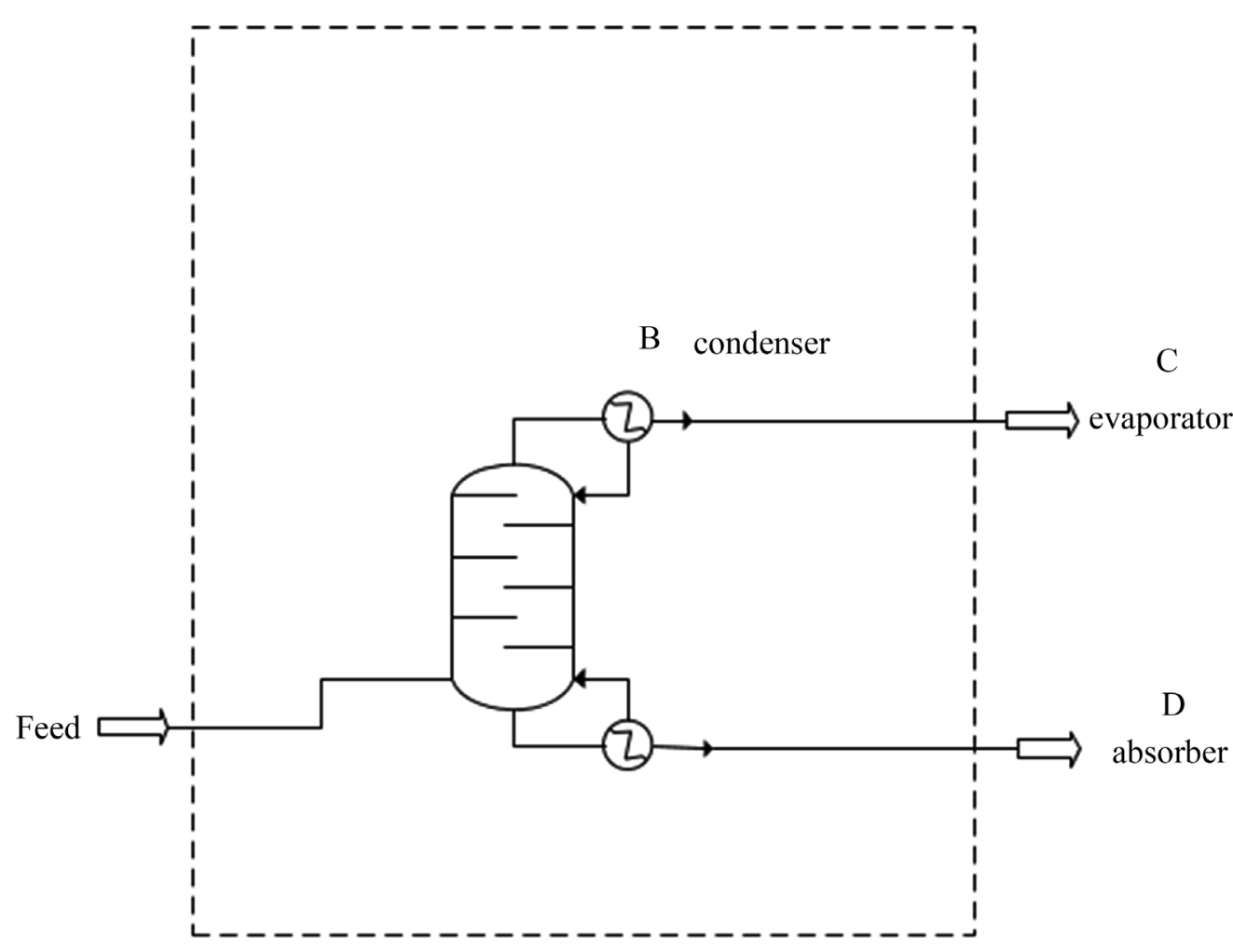

A

Generator

(b) 


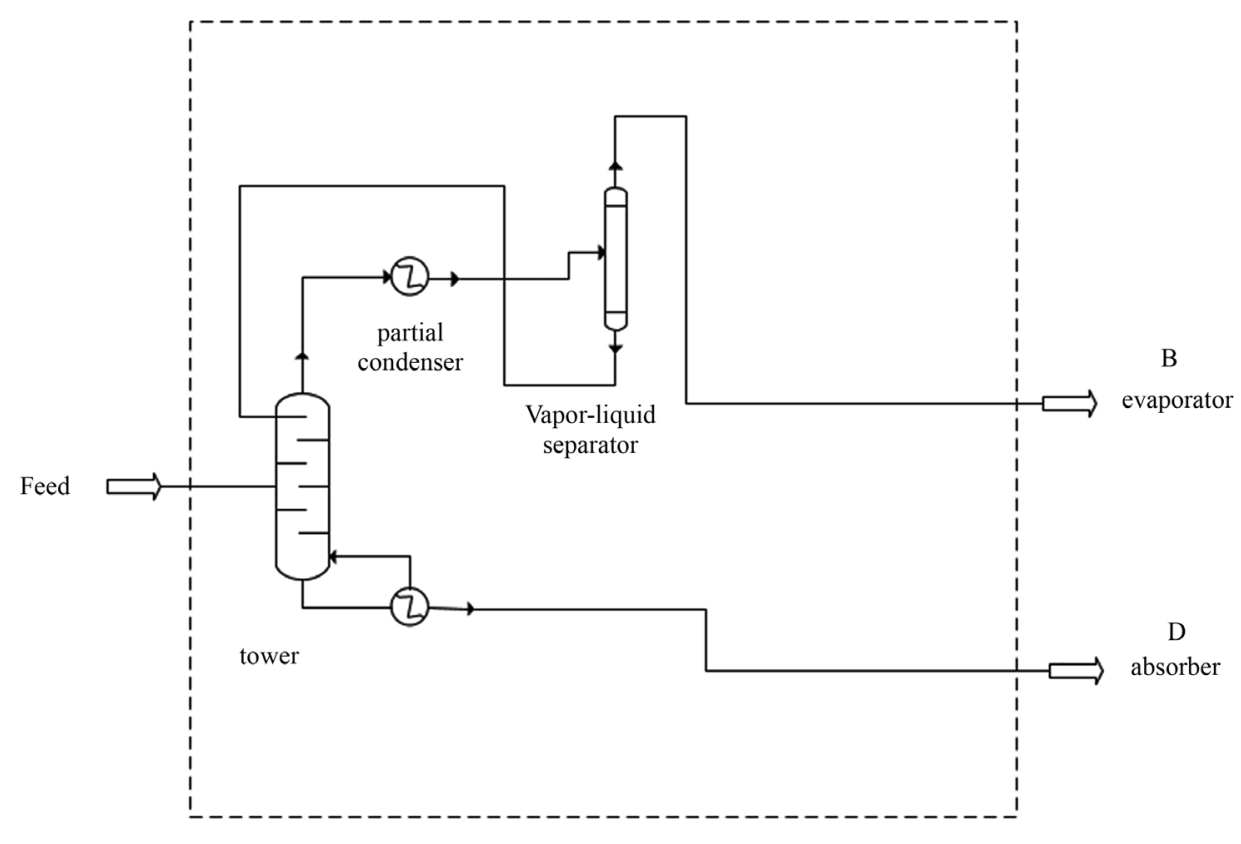

A

Generator

(c)

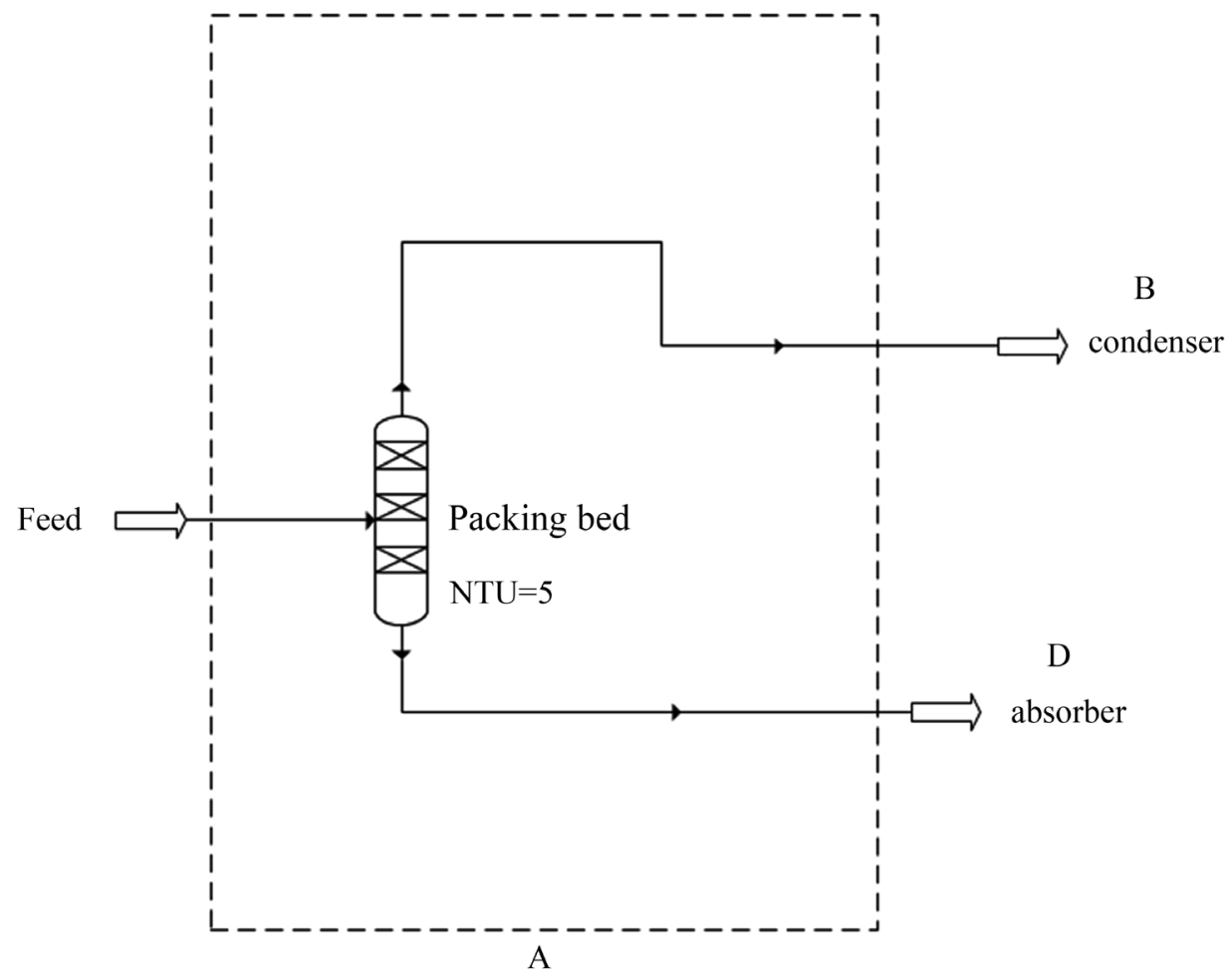

Generator

(d)

Figure 3. Four different kinds of the distillation tower adopted in the present simulations. (a) Schematic diagram of a flash drum; (b) Schematic diagram of a general equilibrium stage tower with a total condenser; (c) Schematic diagram of a packing bed tower with a flash drum (i.e. partial condenser); (d) Schematic diagram of a packing bed tower. 


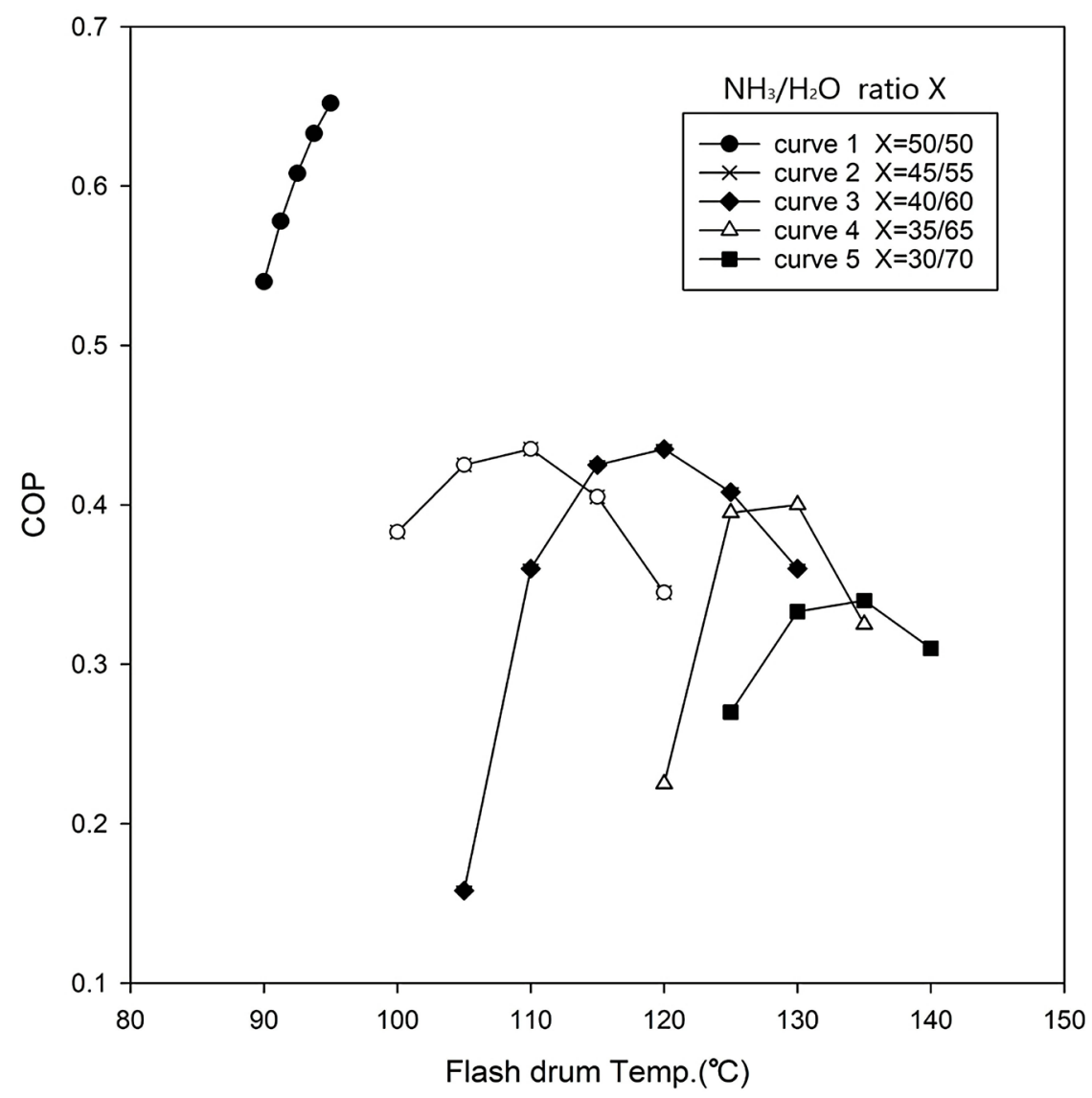

Figure 4. The effects of changing the operating temperatures of the flash drum (Figure 3(a)) on the COPs of the cycle for the various concentration ratios of ammonia to water in the feed solution (i.e. different $X$ values). In this case study, the conventional generator is represented by a flash drum.

When the feed concentration is decreased from $X=50 / 50$ to $X=45 / 55$, the evaporation effect in the evaporator will be diminished gradually when the operating temperature is greater than $110^{\circ} \mathrm{C}$. Hence a maximum COP in curve 2 of Figure 3 is observed. Similar results are obtained for $X=40 / 60, X=35 / 65$ and $X$ $=30 / 70$, where the best operating temperature is located at $120^{\circ} \mathrm{C}, 135^{\circ} \mathrm{C}$ and $140^{\circ} \mathrm{C}$, respectively. One plausible explanation is that as the water contents in the $\mathrm{NH}_{3} / \mathrm{H}_{2} \mathrm{O}$ solution is increased, the energy duty required to evaporate the $\mathrm{NH} 3$ refrigerant in this flash drum is increased. Therefore, the range of operating temperature should also increase gradually as $X$ is changed from $X=50 / 50$ to $X=30 / 70$ as shown in Figure 4. Among these five curves, the highest COP of the cycle is always obtained at $X=50 / 50$.

\subsection{The General Equilibrium Stage Distillation Tower}

In the present paper, two types of distillation tower: 1) the general equilibrium stage tower followed by a total condenser (see Figure 3(b)) and 2) the general equilibrium stage tower equipped followed by a flash drum (i.e. partial condenser, see Figure 3(c)) are employed to simulate the generator in the flow sheet of 
Figure 2. Since the factors of reflux ratio, feed concentration, total stage number, position of feed stage and the energy duty of reboiler are important in determining the separation effect of a distillation tower, therefore the effects of these factors on the COPs of the cycle will be considered as follows.

\subsubsection{The General Equilibrium Stage Tower Followed by a Total Condenser}

At $X=45 / 55$, when the energy duty of reboiler is fixed at $1000 \mathrm{kcal} / \mathrm{hr}$ and the total stage number is equal to five ( $\mathrm{S}=5$ ), the effects of reflux ratio on the COP of the cycle for the various positions of feed stage are shown in Figure 5. Since the $\mathrm{NH}_{3} / \mathrm{H}_{2} \mathrm{O}$ feed solutions enter the lower part of the tower, whose water contents in the vapor phase have more opportunity to be washed by the reflux solution. Therefore, the COPs of curve 1 (i.e. feed at the 4th stage) and curve 2 (i.e. feed at the 3 rd stage) are higher than that of curve 3 (i.e. feed at the 2 nd stage), respectively. In the present paper, the total condenser will be counted as the 1st

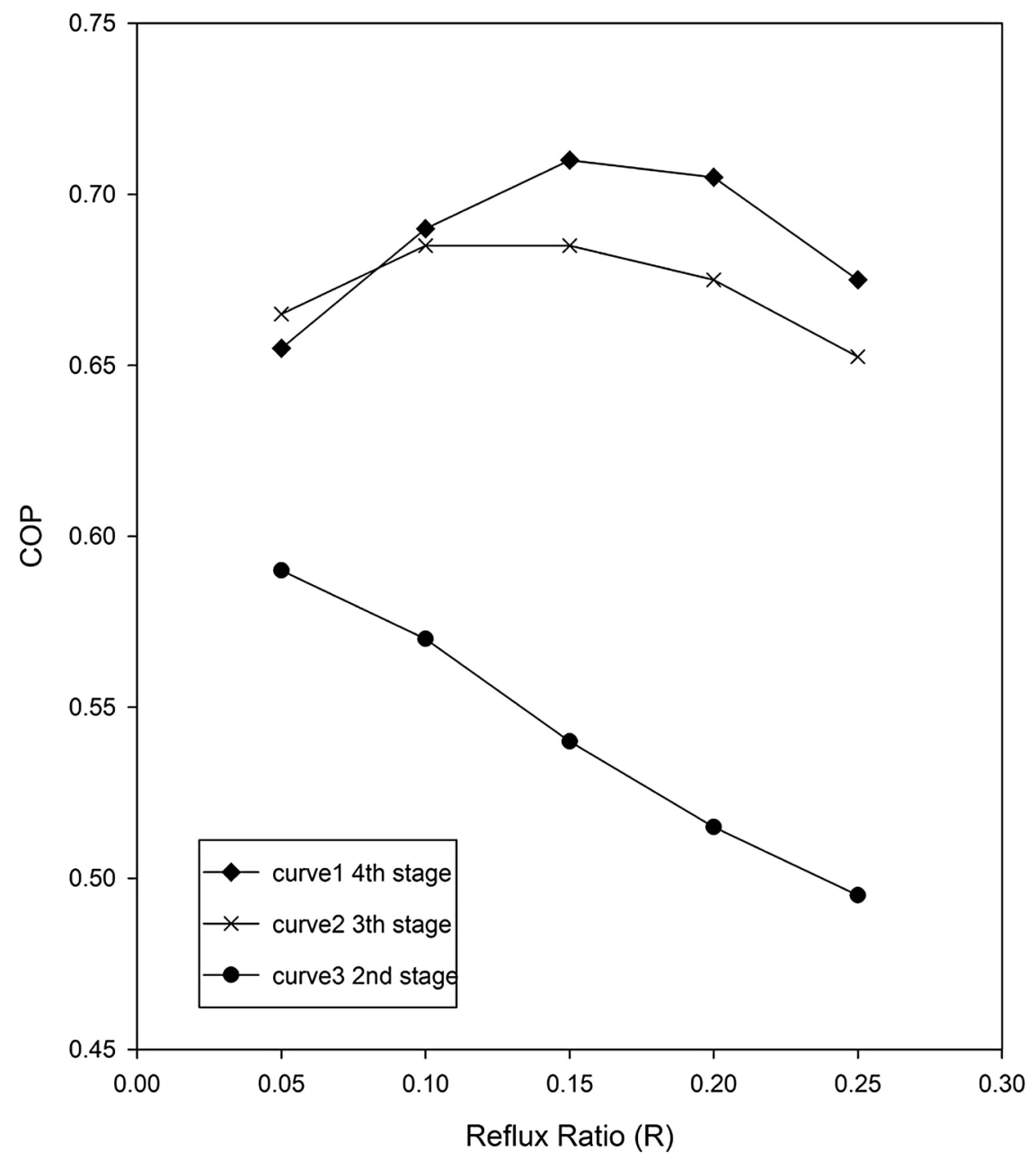

Figure 5. The effects of the reflux ratio of the tower on the COPs of the cycle for the various feed entrance stages, at which $X=45 / 55$ and the energy duty of the reboiler is fixed at $1000 \mathrm{kcal} / \mathrm{hr}$. In this case study, the total stage number of the equilibrium stage tower is equal to five and the pressure of the evaporator is kept at 4.5 bar. 
stage and the reboiler as the 5th stage. In Figure 5, the COPs of curve 1 and curve 2 reach a maximum ( $\mathrm{COP}=0.71$ for curve 1 and 0.67 for curve 2 ) as the reflux ratio increases. When the reflux ratio further increases beyond these optimum values, the amount of ammonia refrigerant existing in the vapor phase is reduced by the over-reflux liquid solution. Consequently, the COP decreases gradually. Curve 3 shows that in the absence of rectifying section in the distillation tower, the COPs of the cycle decreases as the reflux ratio increases.

As the energy duty of reboiler is increased from $1000 \mathrm{kcal} / \mathrm{hr}$ to $1500 \mathrm{kcal} / \mathrm{hr}$, similar results are obtained for those curves shown in Figure 6. Since the more energy supplied to the reboiler, the more amount of ammonia refrigerant is transferred into the vapor phase. Therefore, the COPs for the curves 1, 2 and 3 of Figure 6 are higher than that of those curves shown in Figure 5, respectively.

If the number of the equilibrium stages in the tower is increased from five to ten, the COPs of those curves shown in Figure 7 are found to be higher than those shown in Figure 6. This improvement is likely doe to the increased contact between the vapor phase and the liquid phase the number of equilibrium stage

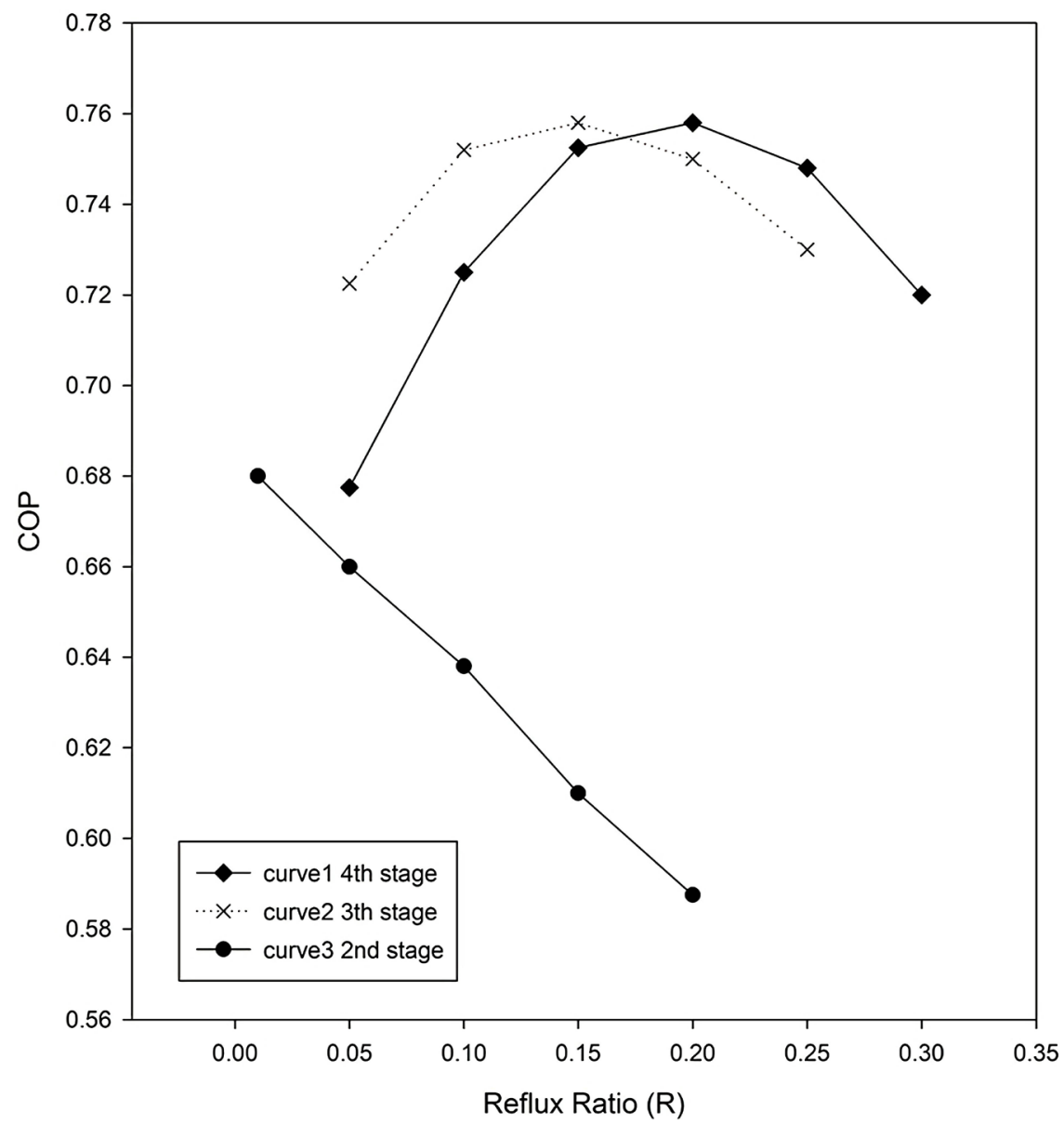

Figure 6. The effects of the reflux ratio of the tower on the COPs of the cycle for the various feed entrance stages, at which $X=45 / 55$ and the energy duty of the reboiler is fixed at $1500 \mathrm{kcal} / \mathrm{hr}$. In this case study, the total stage number of the equilibrium stage tower is equal to five and the pressure of the evaporator is kept at 4.5 bar. 


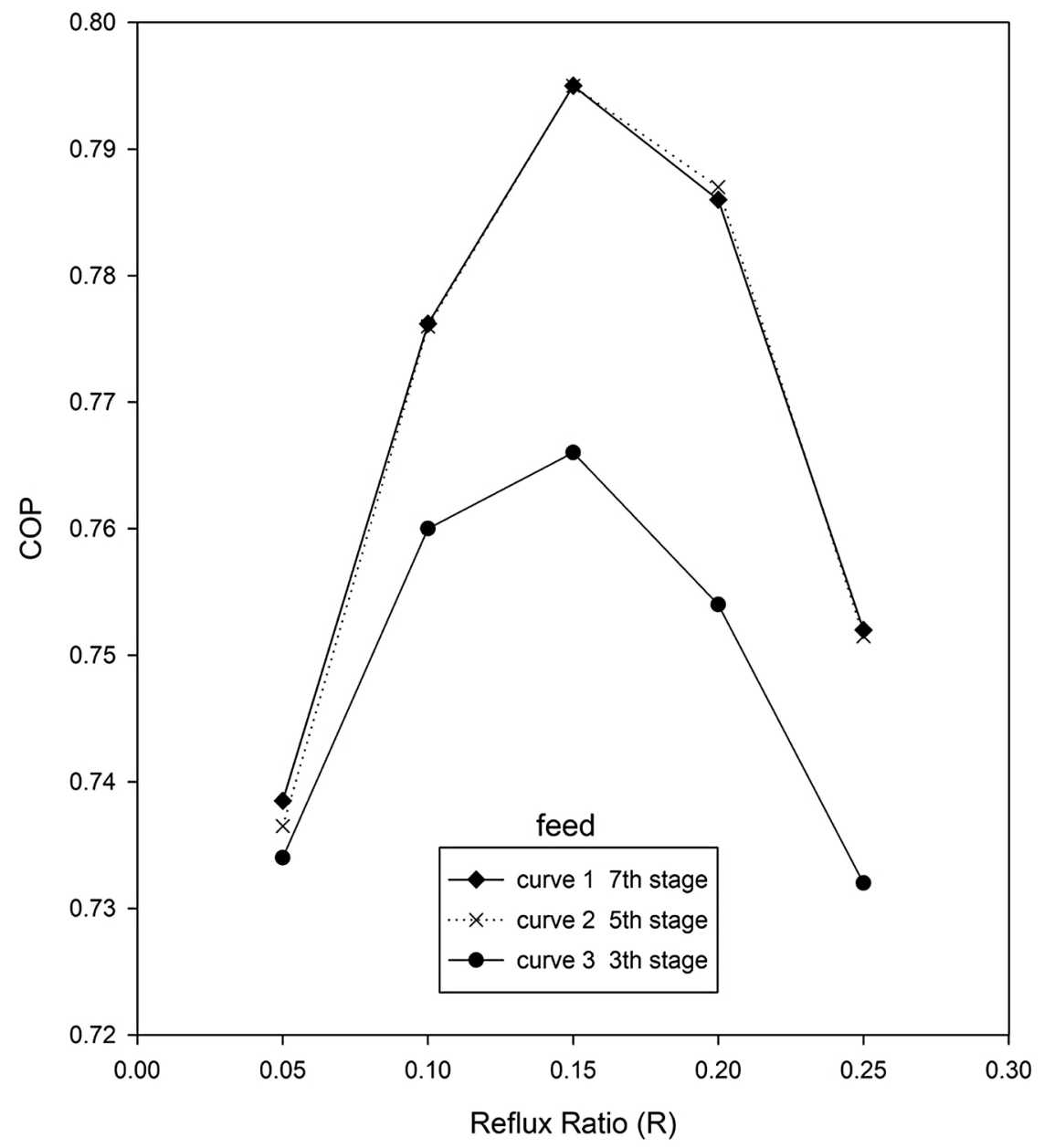

Figure 7. The effects of the reflux ratio of the tower on the COPs of the cycle for the various feed entrance stages, at which $X=45 / 55$ and the energy duty of the reboiler is fixed at $1500 \mathrm{kcal} / \mathrm{hr}$. In this case study, the total stage number of the equilibrium stage tower is equal to ten and the pressure of the evaporator is kept at 4.5 bar.

increases. Similar explanations can be made to explain the maxima existing in these curves of Figure 7.

Simulation result for the case of increasing the $\mathrm{NH}_{3}$ refrigerant concentration in the feed solution from $X=45 / 55$ to $X=50 / 50$ is shown in Figure 8, at which the stage number is equal to five and the energy duty of the reboiler is fixed at $1500 \mathrm{kcal} / \mathrm{hr}$. Comparing the results shown in Figure 8 with these results shown in Figure 6, it is found that the increased amount of refrigerant in the feed solution can improve the COPs to about $10 \%$ when the reflux ratios of distillation tower are smaller than 0.1. In Figure 8, again, since the over-reflux liquid reduces the amount of ammonia vapor above the feed stage, the obtained COPs for all of these three curves will decrease with the increase of reflux ratio. Because deficient in rectifying function for feed solution enters at the second stage of the tower, we also found that curve 3 exhibits the steepest decline slope among the three curves of Figure 8. The result of increasing the number of stages from five to ten is illustrated in Figure 9. Unlike the case of $X=45 / 55$ as 


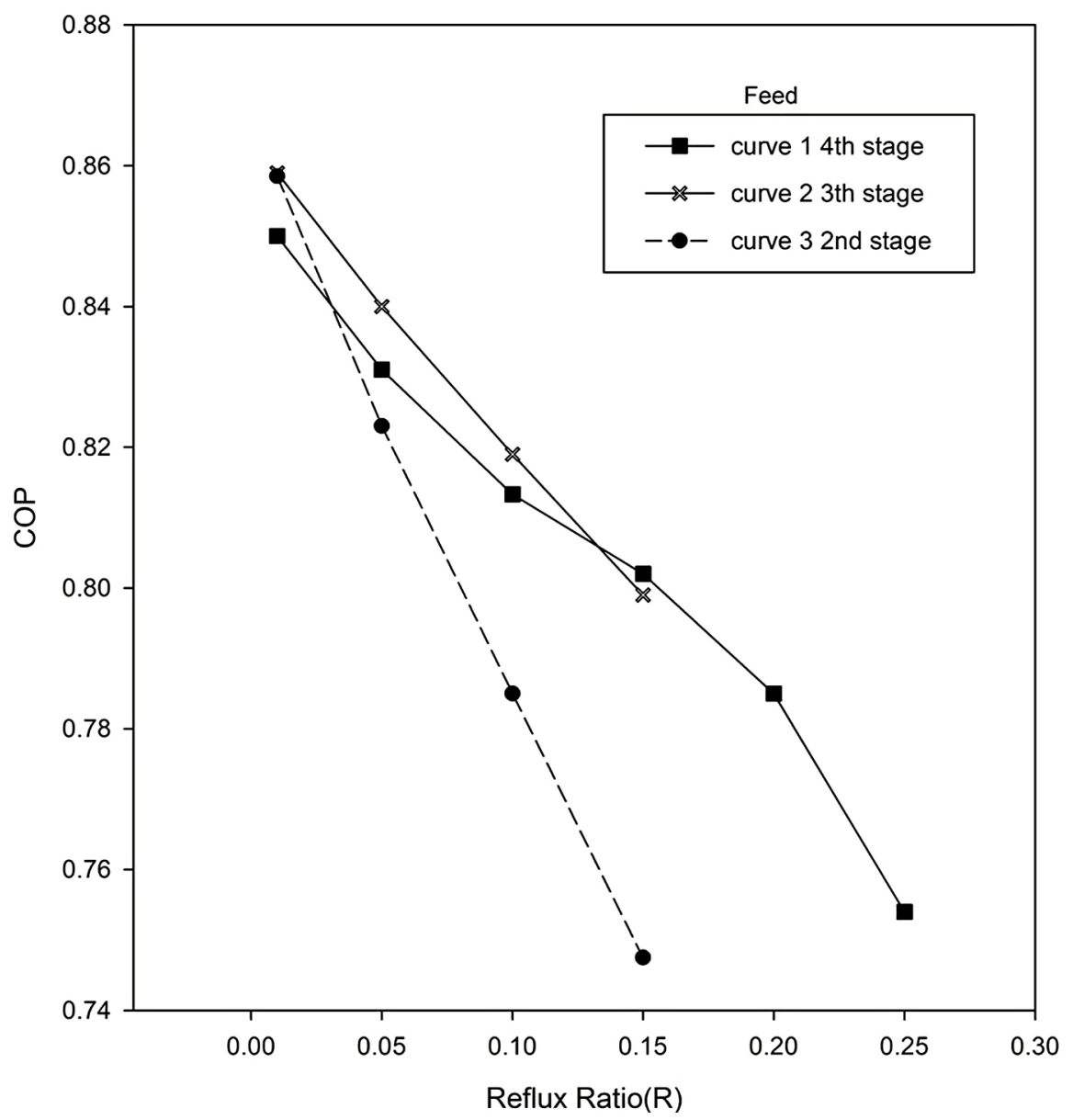

Figure 8. The effects of the reflux ratio of the tower on the COPs of the cycle for the various feed entrance stages, at which $X=50 / 50$ and the energy duty of the reboiler is fixed at $1500 \mathrm{kcal} / \mathrm{hr}$. In this case study, the total stage number of the equilibrium stage tower is equal to five and the pressure of the evaporator is kept at 5.4 bar.

shown in Figure 8, it is shown in Figure 9 that no increase in COPs with increasing reflux ratio when the feed solution enters the tower at the 4th stage. As the energy duty of the reboiler is increased from $1000 \mathrm{kcal} / \mathrm{hr}$ to $2000 \mathrm{kcal} / \mathrm{hr}$, more ammonia refrigerant is distilled into the vapor phase. Thus, the COP of the cycle is enhanced efficiently.

\subsubsection{The General Equilibrium Stage Tower Followed by a Partial Condenser}

From the results of the above simulation, it is found that the lower the reflux ratio of the total condenser the higher the COPs of the cycle. This trend indicates that most of the refrigerant entering this total condenser would be in the vapor phase if a high COP value is desired. Therefore, it suggests to us that a simple flash drum (i.e. partial condenser) could be employed to replace the total condenser at the top of the distillation tower in the following case study. By using a suitable temperature control, the vapor phase of ammonia refrigerant can be easily separated from that of the liquid phase in this flash drum. 


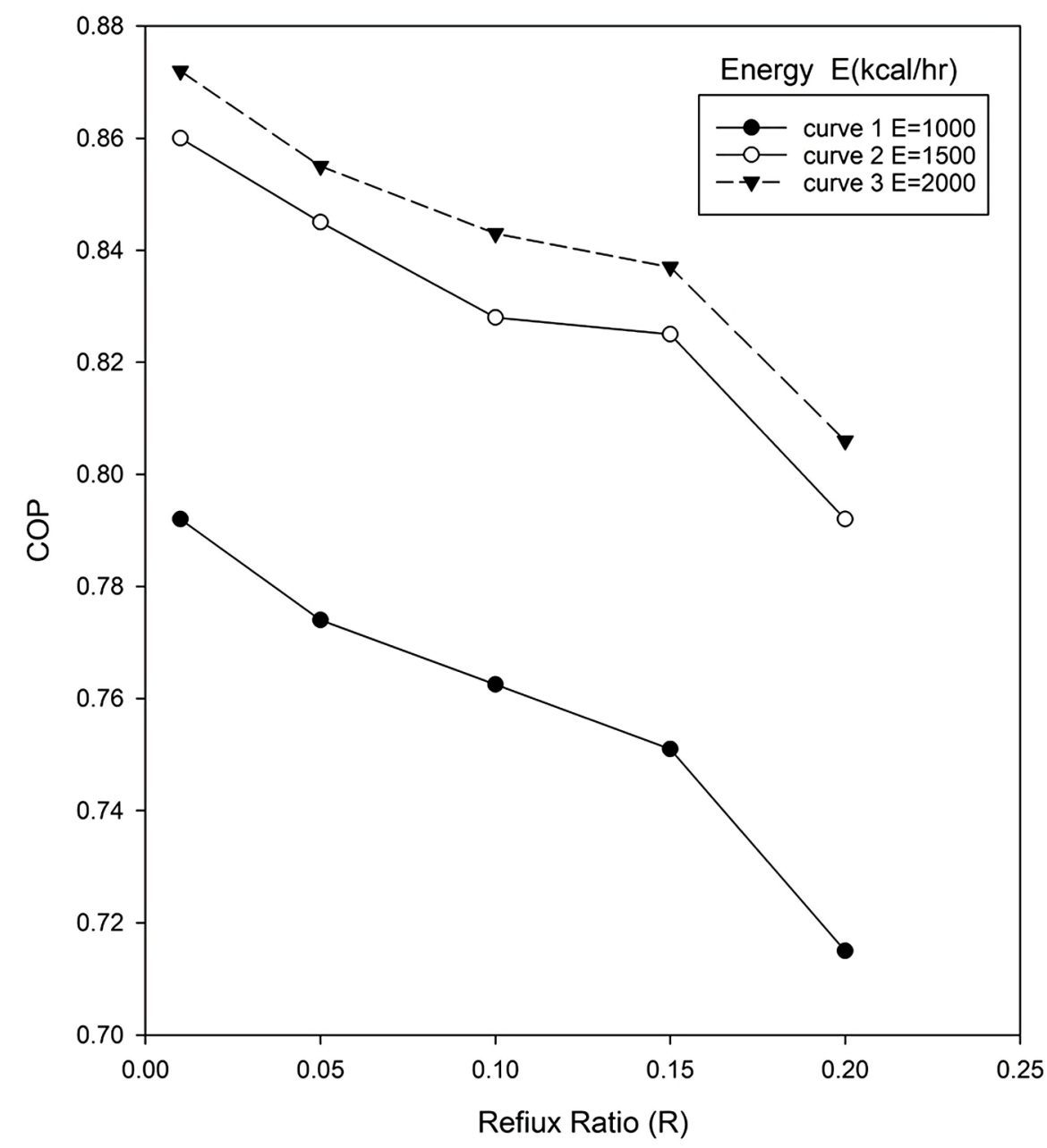

Figure 9. The effects of the reflux ratio of the tower on the COPs of the cycle for the various values of the energy duty of the reboiler, at which $X=50 / 50$ and the feed enters the tower at the 5th stage. In this case study, the total stage number of the equilibrium stage tower is equal to ten and the pressure of the evaporator is kept at 5.4 bar.

As shown in Figure 3(c), likes the partial condenser of the conventional distillation tower, this flash drum provides an additional equilibrium stage at which the liquid and the vapor phases of $\mathrm{NH}_{3} / \mathrm{H}_{2} \mathrm{O}$ mixture can be easily separated. Because the temperature of this flash drum determines the concentration of ammonia in the vapor phase (which passes through the condenser and evaporator thereafter in the flow sheet), its effect on the COPs of the cycle will be simulated first here. The results for $X=45 / 55$ and the energy duty fixed at 1500 $\mathrm{kcal} / \mathrm{hr}$ are shown in Figure 10. It is shown that the COP of the cycle decreases with increasing temperature of the flash drum. This can be explained by the fact that the vapor phase is diluted as more water enters the vapor phase at higher temperatures.

Also, as shown in Figure 10, as the number of stages increases, the concentration of ammonia in the vapor phase also increases. Therefore, the COPs of the cycle can be increased with the increase of the stage number. When the mass 


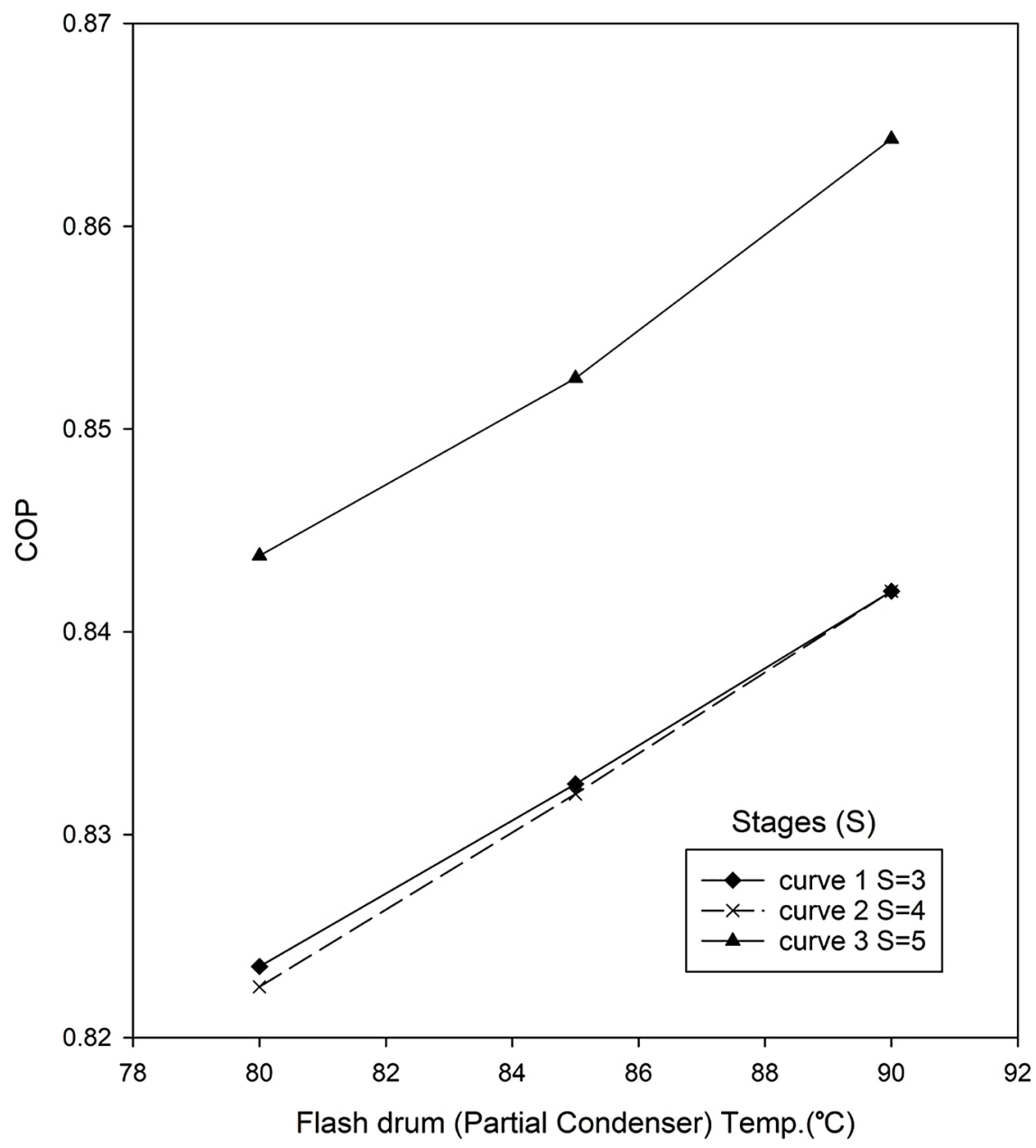

Figure 10. The effects of the flash drum (i.e. partial condenser) temperature on the COPs of the cycle for the various stage numbers of the tower, at which $X=50 / 50$ and the energy duty of the reboiler is fixed at $1500 \mathrm{kcal} / \mathrm{hr}$. In this case study, the feed entrance positions for the curves 1, 2 and 3 are at 3rd, 2nd and 1st stage, respectively. The pressure of the evaporator is kept at 5.4 bar.

flow rate ratio $X$ is increased from $X=45 / 55$ to $X=50 / 50$, Figure 11 demonstrates the effect of energy duty of the reboiler on the COPs. It is found that the COPs of the cycle can be increased significantly (i.e. COP is increased from 0.71 to 0.755 at $55^{\circ} \mathrm{C}$ ) when the energy duty is increased from $1000 \mathrm{kcal} / \mathrm{hr}$ (curve 1) to $1500 \mathrm{kcal} / \mathrm{hr}$ (curve 2). However, if this energy duty is further increased to $1750 \mathrm{kcal} / \mathrm{hr}$ (curve 3), the COPs of is slightly decreased. This trend may occur due to the fact that the distillation effect promoted in the tower could be counterbalanced by the limited refrigeration function performed by the ammonia in the evaporator as we found in our simulations. Again, similar trends seen in Figure 10 are observed in Figure 11, in which all COPs of three curves shown decrease with the increasing flash drum temperature.

\subsubsection{Packed-Bed Tower}

It is known that the packed-bed tower exhibits better characteristics such as 


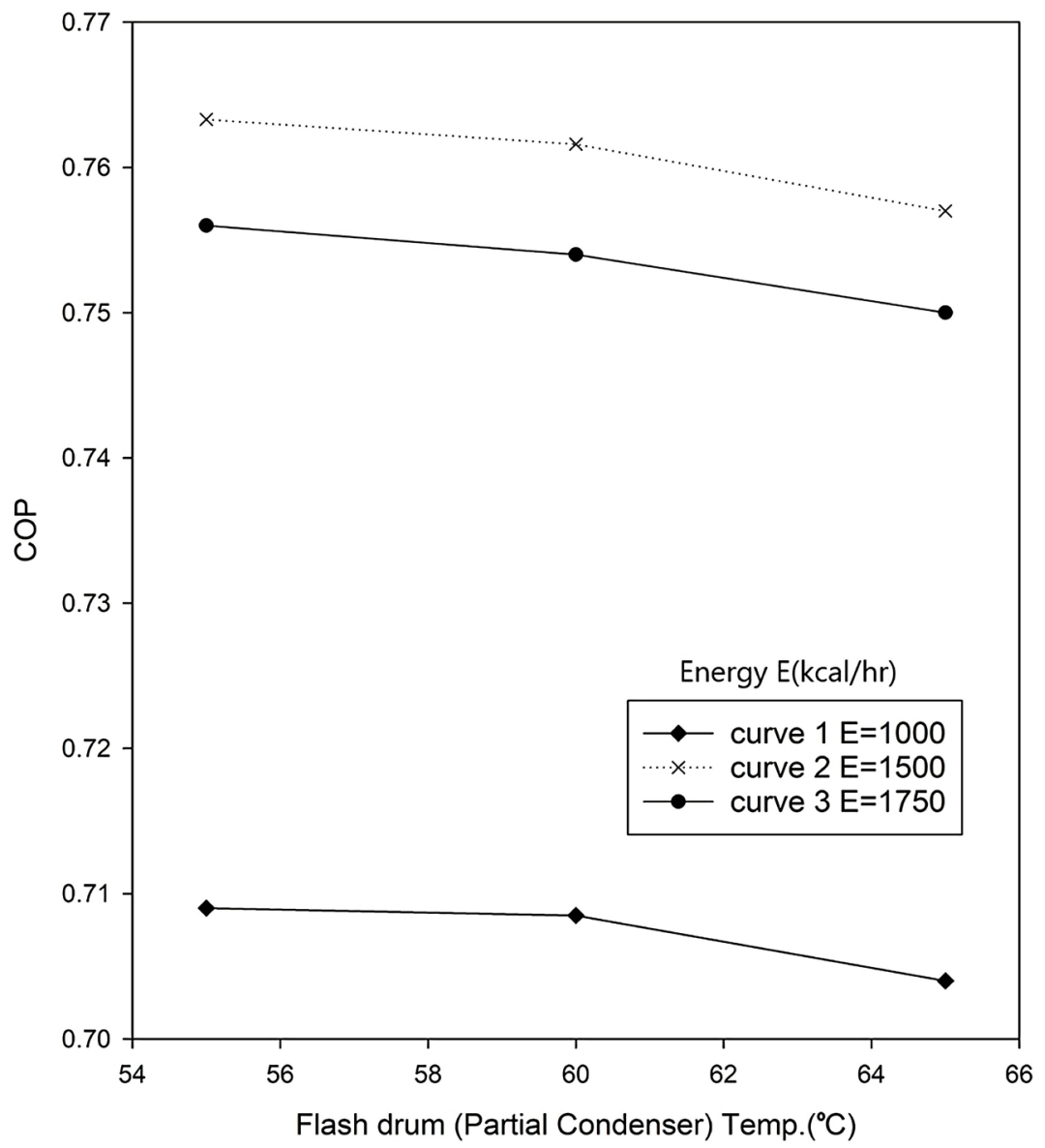

Figure 11. The effects of the flash drum (i.e. partial condenser) temperature on the COPs of the cycle for the various values of the energy duty of the reboiler, at which $X=50 / 50$. In this case study, the total stage number of the packing bed tower is equal to five and the feed enters the tower at the $3 \mathrm{rd}$ stage. The pressure of the evaporator is kept at 5.4 bar.

smaller pressure drop and higher operating temperature than those of the general equilibrium stage distillation tower. Therefore, we also replace the generator with a packed-bed tower as shown in Figure 3(d). Figure 12 shows the simulation result of the effect of the energy duty on COPs for $X=45 / 55$, where the number of the theoretical equilibrium stage unit of the packing bed tower is equal to five (i.e. $\mathrm{NTU}=5$ ) and the feed stage is chosen at $\mathrm{S}=3$. In Figure 12, we find that the COPs of the cycle can be increased with increasing energy duty or the operating temperature due to the increased concentration of $\mathrm{NH}_{3}$ in the vapor phase of the packing bed. The highest COP of 0.86 is obtained at the temperature of $90^{\circ} \mathrm{C}$ and the energy duty of $1750 \mathrm{kcal} / \mathrm{hr}$. Since the upper limit saturated temperature corresponding to the assumed pressure $17 \mathrm{bar}$ is $90^{\circ} \mathrm{C}$, the temperature range adopted in the present simulation is chosen between $80^{\circ} \mathrm{C}$ and $90^{\circ} \mathrm{C}$.

In addition to the above simulations of using different types of the distillation tower as shown in Figures 3(a)-(d), we had also conducted simulations systematically under different temperature, reflux ratio and the equilibrium stage 


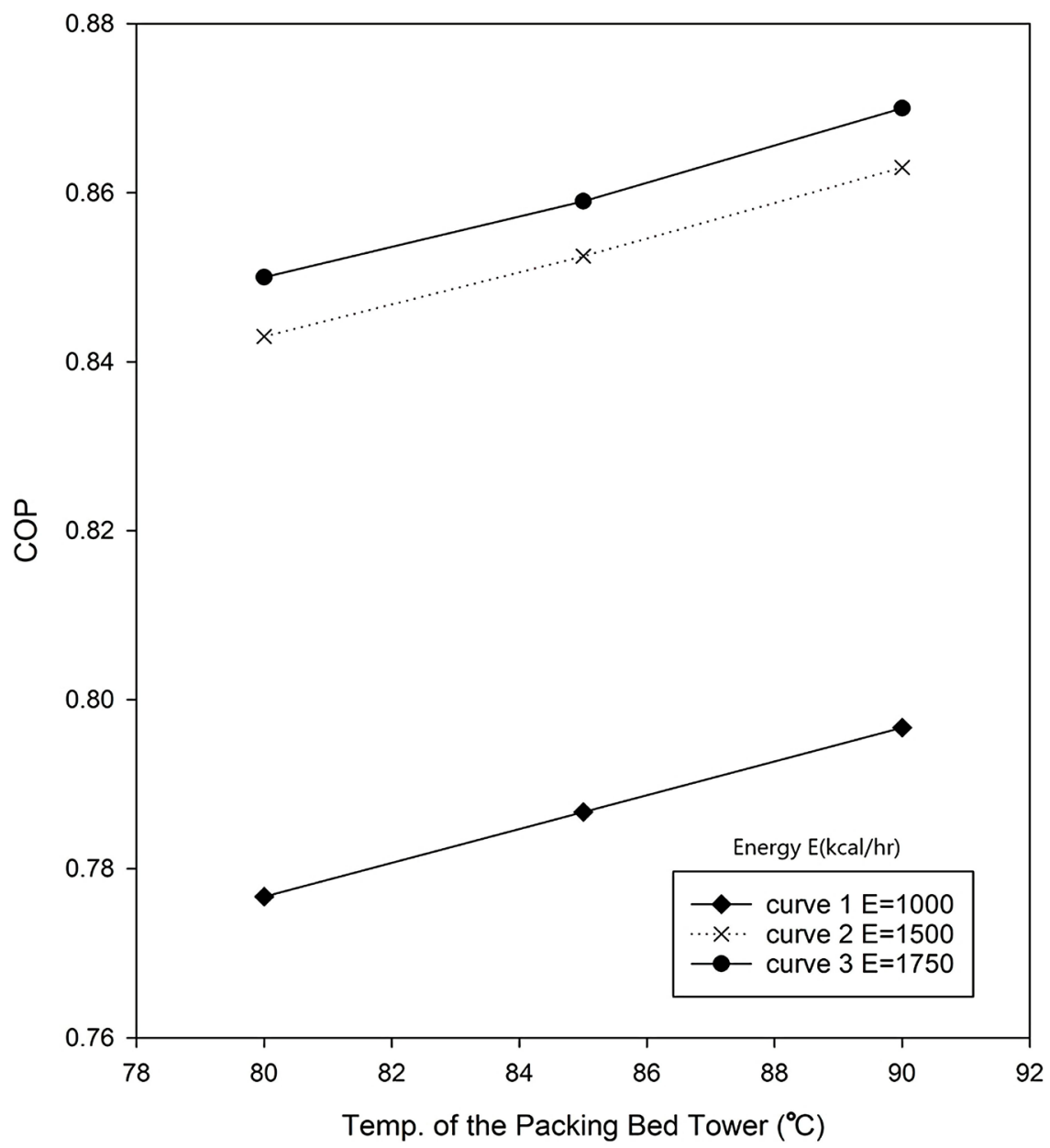

Figure 12. The effects of the temperature of the packing bed tower on the COPs of the cycle for the various values of the energy duty of the reboiler, at which $X=45 / 55$. In this case study, the total stage number of the packing bed tower is equal to five and the feed enters the tower at the $3 \mathrm{rd}$ stage. The pressure of the evaporator is kept at 4.5 bar.

adopted for the distillation towers shown in Figures 3(a)-(d) for $X=45 / 55$ and $X=50 / 50$. The highest COPs are summarized in Table 1 and Table 2, respectively. From the data shown in these two tables, we can find that the case of replacing the generator by a packed-bed tower with NTU $=5$ can give the highest COPs in general among those four modified distillation towers as shown in Figures $3(\mathrm{a})$-(d).

\section{Conclusion}

With the available software Aspen version-10.0, the computer simulation of a water-ammonia absorption cycle for refrigeration has been carried out in the present paper. It is found that the distillation tower can replace the generator successfully and therefore can increase the COPs of the cycle efficiently, due to its capability of reducing the water contents in the vapor phase of ammonia refrigerant. A comparative study is done for two types of a distillation tower equipped with a total condenser and a distillation tower equipped with a flash 
Table 1. The highest COPs obtained in the present simulations under different operating values of temperature, reflux ratio and the equilibrium stage adopted for the distillation towers shown in Figures 3(a)-(d) for $X=45 / 55$.

\begin{tabular}{|c|c|c|c|}
\hline Case study & Generator replacement & Operating conditions for $X=45 / 55$ & COPs for $X=45 / 55$ \\
\hline Figure 3(a) & Flash drum & Temperature: $110^{\circ} \mathrm{C}$ & 0.439 \\
\hline Figure 3(b) & $\begin{array}{l}\text { The general equilibrium } \\
\text { stage tower followed by } \\
\text { a total condenser }\end{array}$ & $\begin{array}{c}\text { The number of equilibrium stage: } 5 \\
\text { Feed stage: } 3 \\
\text { Reflux ratio: } 0.15 \\
\text { Energy duty: } 1750 \mathrm{kcal} / \mathrm{hr}\end{array}$ & 0.797 \\
\hline Figure $3(c)$ & $\begin{array}{l}\text { The general equilibrium } \\
\text { stage tower followed by } \\
\text { a flash drum (partial } \\
\text { condenser }\end{array}$ & $\begin{array}{c}\text { The number of equilibrium stage: } 5 \\
\text { Feed stage: } 3 \\
\text { Temperature of flash drum: } 55^{\circ} \mathrm{C} \\
\text { Energy duty: } 1500 \mathrm{kcal} / \mathrm{hr}\end{array}$ & 0.791 \\
\hline Figure $3(d)$ & $\begin{array}{c}\text { The packing bed tower } \\
\text { with NTU }=5\end{array}$ & Temperature: $90^{\circ} \mathrm{C}$ & 0.862 \\
\hline
\end{tabular}

Table 2. The highest COPs obtained in the present simulations under different operating values of temperature, reflux ratio and the equilibrium stage adopted for the distillation towers shown in Figures 3(a)-(d) for $X=50 / 50$.

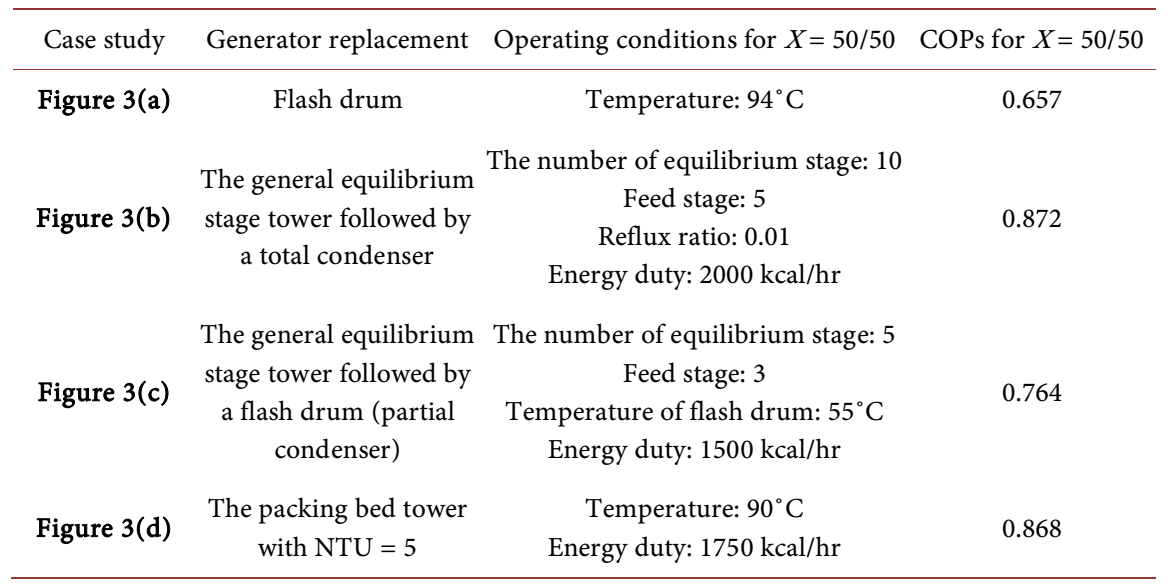

drum (i.e. a partial condenser). The tower equipped with a partial condenser provides a better separation effect on the water contents in the vapor phase of refrigerant than that of the tower equipped with total condenser. Therefore, the former equipment provides higher COPs of the cycle than that of the latter one in general. The replacement of the generator by the packed-bed tower in this water-ammonia absorption cycle can give the best COPs.

\section{Acknowledgements}

Financial support received from the Ministry of Science and Technology (MOST) of Taiwan is greatly appreciated.

\section{Conflicts of Interest}

The authors declare no conflicts of interest regarding the publication of this paper. 


\section{References}

[1] Arora, C.P. (2009) Refrigeration and Air Conditioning. Third Edition, The McGraw Hill Education Pvt. Ltd., New York, 437-442.

[2] Shukla, A., Mishara, A., Shukla, D. and Cauhan, K. (2015) C.O.P Derivation and Thermondymanic Calculation of Ammonia-Water Vapor Absorption Refrigeration System. International Journal of Mechanical Engineering and Technology, 6, 72-81.

[3] Rossa, J.A. and Bazzo, E. (2009) Thermodynamic Modeling of an Ammonia-Water Absorption System Associated with a Microturbine. International Journal of Thermodynamics, 12, 38-43.

[4] Kong, T.D.F., Liu, J.H., Zhang, L., He, H. and Fang, Z.Y. (2010) Thermodynamic and Experimental Analysis of an Ammonia-Water Absorption Chiller. Energy and Power Engineering, 2, 298-305. https://doi.org/10.4236/epe.2010.24042

[5] Hong, D., Tang, L., He, Y. and Chen, G. (2010) A Novel Absorption Refrigeration Cycle. Applied Thermal Engineering, 30, 2045-2050. https://doi.org/10.1016/j.applthermaleng.2010.05.010

[6] Ouadha, A. and EI-Gotni, Y. (2013) Integration of an Ammonia-Water Absorption Refrigeration System with a Marine Diesel Engine: A Thermodynamic Study. Procedia Computer Science, 19, 754-761. https://doi.org/10.1016/j.procs.2013.06.099

[7] Oza, V.H. and Bhatt, N.M. (2018) Thermodynamic Analysis of Ammonia-Water Absorption Refrigeration System with Ejector. International Journal of Mechanics and Solids, 13, 95-110.

[8] Kaewpraduba, S., Sanguandueana, P., Katesuwana, W., Chimresa, N., Punyasukhanandab, P., Asirvathamc, L.G., Mahiand, O., Dalkilice, A.S. and Wongwisesa, S. (2018) Absorption Refrigeration System Using Engine Exhaust Gas as an Energy Source. Case Studies in Thermal Engineering, 12, 797-804.

https://doi.org/10.1016/j.csite.2018.10.003

[9] Wijaksana, H., Winaya, I.N.S., Sucipta, M. and Ghurri, A. (2019) The Investigation of Influence Ammonia Concentration Variations to the Performance of a Pump Less Ammonia-Water Absorption Refrigeration System with Water Flooding Evaporator. AIP Conference Proceedings, 2062, Article ID: 020053. https://doi.org/10.1063/1.5086600

[10] Babu, M.S., Prasad, L.D., Prasad K.S.D., Vikas, M. and Kishore, P.S. (2019) Performance of Ammonia-Water Vapor Absorption Refrigeration System. Journal of Emerging Technologies and Innovative Research, 6, 207-214.

[11] Kaushik, S.C. and Bhardwaj, S.C. (1982) Theoretical Analysis of Ammonia-Water Absorption Cycles for Refrigeration and Space Conditioning Systems. Energy Research, 6, 205-225. https://doi.org/10.1002/er.4440060302

[12] Clerx, M. and Trezek, G.J. (1987) Performance of an Aqua-Ammonia Absorption Solar Refrigerator at Sub-Freezing Evaporator Conditions. Solar Energy, 39, 379-389. https://doi.org/10.1016/S0038-092X(87)80056-7

[13] Best, R. and Hernandez, J. (1991) Experimental Studies on the Operating Characteristics of an Ammonia-Water Absorption System for Solar Cooling. Applied Energy, 69, 153-160.

[14] Raghuvanshi, S. and Maheshwari, G. (2011) Analysis of Ammonia-Water $\left(\mathrm{NH}_{3}\right.$ $\mathrm{H}_{2} \mathrm{O}$ ) Vapor Absorption Refrigeration System Based on First Law of Thermodynamics. International Journal of Scientific \& Engineering Research, 2, 39-45.

[15] Cai, W.H., Sen, M. and Paolucci, S. (2012) Dynamic Simulation of an Ammonia-Water Absorption Refrigeration System. Industrial \& Engineering Chemistry 
Research, 51, 2070-2076. https://doi.org/10.1021/ie200673f

[16] Habibzadeh, A., Jafarmadar, S., Rashidi, M.M., Rezaei, S.S. and Aghagoli, A. (2017) Energy and Exergy Analysis of an Ejector-Absorption Refrigeration Cycle with Using $\mathrm{NH}_{3}-\mathrm{H}_{2} \mathrm{O}$ as the Working Fluids. Journal of Environmental Friendly Materials, 1, 45-54.

[17] (2017) Aspen plus Version-10.0. Aspen Technology Inc., Houston.

[18] Darwish, N.A., Al-Hashimi, S.H. and Al-Mansoori, A.S. (2008) Performance Analysis and Evaluation of a Commercial Absorption-Refrigeration Water-Ammonia (ARWA) System. International Journal of Refrigeration, 31, 1214-1223. https://doi.org/10.1016/j.ijrefrig.2008.02.005

[19] Chang, Y.I., Wu, L.C. and Wu, C.C. (2000) The Advantage of Using a Distillation Tower in an Ammonia-Water Absorption Cycle for Refrigeration. Chinese Journal of Chemical Engineering, 31, 193-197. 